\title{
Biocontrol Activity of Three Pseudomonas in a Newly Assembled Collection of Phytophthora infestans Isolates
}

\author{
Mout De Vrieze,, ${ }^{1,2}$ Ramona Gloor,2,3 Josep Massana Codina,,2 Stefano Torriani, ${ }^{3}$ Katia Gindro, ${ }^{2}$ Floriane L'Haridon, ${ }^{1}$ \\ Aurélien Bailly, ${ }^{4}$ and Laure Weisskopf ${ }^{1, \dagger}$ \\ ${ }^{1}$ Department of Biology, University of Fribourg, Chemin du Musée 10, CH-1700 Fribourg, Switzerland \\ ${ }^{2}$ Research Division Plant Protection, Agroscope, Route de Duillier 60, CH-1260 Nyon, Switzerland \\ ${ }^{3}$ Syngenta Crop Protection AG, Schaffhauserstrasse 101, CH-4332 Stein, Switzerland \\ ${ }^{4}$ Department of Plant and Microbial Biology, University of Zürich, Zollikerstrasse 107, CH-8008 Zurich, Switzerland \\ Accepted for publication 30 April 2019.
}

\begin{abstract}
Late blight caused by the oomycete Phytophthora infestans constitutes the greatest threat to potato production worldwide. Considering the increasing concerns regarding the emergence of novel fungicide-resistant genotypes and the general demand for reducing inputs of synthetic and copper-based fungicides, the need for alternative control methods is acute. Several bacterial antagonists have shown anti-Phytophthora effects during in vitro and greenhouse experiments. We report the effects of three Pseudomonas strains recovered from field-grown potatoes against a

leaf disc experiments on Black's differential set. The mycelial growth of all $P$. infestans isolates was fully inhibited when co-cultivated with the most active Pseudomonas strain (R47). Moreover, the isolates reacted differently to exposure to the less active Pseudomonas strains (S19 and R76). Leaf disc infection experiments with six selected $P$. infestans isolates showed that four of them, including highly virulent and fungicideresistant ones, could be efficiently controlled by different potato-associated Pseudomonas strains.
\end{abstract} collection of $P$. infestans isolates assembled for this study. The collection comprised 19 P. infestans isolates of mating types A1 and A2 greatly varying in fungicide resistance and virulence profiles as deduced from
Keywords: biocontrol, fungicide resistance, mating type, pathogen aggressiveness, Phytophthora infestans, Pseudomonas, virulence
Since its emergence in the mid-nineteenth century, late blight has been and remains the most devastating disease of potato worldwide. Caused by the extremely potent heterothallic oomycete Phytophthora infestans (Mont.) de Bary, late blight affects potato leaves, stems, and tubers. Its fast life cycle, which is supported by the massive production of large wind-dispersible spores called sporangia or small motile spores called zoospores, enables this pathogen to infect entire fields of potato plants within a few days (Fry 2008). P. infestans can readily survive during winter via the latent infection of tubers or via the production of oospores, which can survive for several years in the soil. Oospores are the result of sexual reproduction, which occurs when the two mating types, A1 and $\mathrm{A} 2$, are present. Although it is a rather rare event, it can have significant implications for disease management because it increases the genetic diversity of the population of $P$. infestans and has adaptive potential (McDonald and Linde 2002). Each year, global economic losses caused by late blight amount to an estimated $\$ 4$ billion (Judelson and Blanco 2005) and €9 billion in control costs and harvest losses (Haverkort et al. 2009). A substantial share of the costs generated by late blight is attributable to the purchase of fungicides. With conventional farming, control is based on the

†Corresponding author: L. Weisskopf; laure.weisskopf@unifr.ch

Funding: Swiss National Science Foundation grants 149271, 177093, and 179310 to L. Weisskopf, and the Agroscope Research Program MicBioDiv.

Mout De Vrieze and Ramona Gloor contributed equally to this work.

*The $\boldsymbol{e}$-Xtra logo stands for "electronic extra" and indicates that two supplementary figures and two supplementary tables are published online.

The author(s) declare no conflict of interest. repeated application of synthetic fungicides throughout the cropping season. With organic farming, copper-based fungicides are applied in some countries, but other countries have banned such copper-based products because of their environmental toxicity, which leaves organic potato producers with no solution to control this important disease. In Europe and North America, both mating types were detected in the 1970s, and evidence of sexual reproduction in $P$. infestans populations on both continents was reported in the early 1990s (Drenth et al. 1994; Goodwin et al. 1998). Increasing concern regarding resistance development toward fungicides and the growing societal demand for environmentally sound agricultural practices have urged the development of novel control methods and strategies.

Several studies have explored alternative, more durable, and ecologically pertinent solutions for late blight control. Potential options evaluated include the induction of plant resistance by means of elicitors such as elicitin, BABA, COS-OGA, or various microorganisms comprising mycorrhiza and yeasts (Clinckemaillie et al. 2017; Du et al. 2015; Floryszak-Wieczorek et al. 2015; Gallou et al. 2011; Hadwiger et al. 2015). Among these different plant inducers, both BABA and phosphite have shown promising results during greenhouse and field experiments (Forrer et al. 2017; Liljeroth et al. 2010; Si-Ammour et al. 2003). Molecular studies have revealed that both compounds cause rapid and extensive transcriptional reprograming in potato, although the plant hormonal pathways underlying phosphite-induced resistance remain to be elucidated (Bengtsson et al. 2014; Burra et al. 2014). In addition to these plant resistance inducers, some microorganisms with direct anti-Phytophthora activity have been described. Potential biocontrol candidates for which inhibitory activity against $P$. infestans was demonstrated include fungal Trichoderma species, the oomycete Pythium oligandrum, and various bacterial species that predominantly belong to the genera Bacillus and Pseudomonas (Caulier et al. 2018; Horner et al. 2012; Hultberg et al. 2010; Hunziker et al. 2015; Morrison et al. 2017; Yao et al. 2016). 
We previously tested the efficacy of several potato-associated Pseudomonas strains on in vitro mycelial growth of $P$. infestans. As in many other such studies, experiments were performed on a single isolate of $P$. infestans, thus neglecting to consider the potentially high diversity of $P$. infestans populations encountered under field conditions when evaluating the efficacy of biocontrol agents. In the present study, a new collection of $P$. infestans isolates was assembled by harvesting symptomatic leaf samples in infected fields. All retrieved isolates were characterized according to aggressiveness, virulence, fungicide resistance, mating type, multilocus genotype, and other virulence-associated traits. We then selected three Pseudomonas bacterial strains that showed varying inhibitory effects on the $P$. infestans isolate tested previously and analyzed their antiPhytophthora activity on the newly assembled isolate collection to assess the breadth of activity of these potato-associated Pseudomonas strains. We also investigated whether susceptibility to the bacterial strains would be correlated to any of the aforementioned P. infestans isolate characteristics.

\section{MATERIALS AND METHODS}

Sampling and isolation of $\boldsymbol{P}$. infestans. Isolates of $P$. infestans were collected from May to August 2015 in 16 different locations in Switzerland. Isolates were collected by sampling symptomatic leaves from infected fields. In two locations, samples were taken at two and three different time points. Small pieces of leaves showing lesions were cut and pressed between two potato slices for transport to the laboratory. The pieces were placed on new potato tuber slices on arrival, and newly grown mycelium was collected, placed on selective rye agar medium prepared as follows: $200 \mathrm{~g}$ of rye grains were boiled in distilled water for $1 \mathrm{~h}$, after which the filtered solution was adjusted to 1 liter with distilled water. Subsequently, $15 \mathrm{~g} /$ liter of agar powder (agar-agar; ERNE surface AG) was added, and the solution was autoclaved before being supplemented with nystatin (50,000 units/liter; SigmaAldrich), rifampicin (10 $\mu \mathrm{g} / \mathrm{ml}$; Applichem Panreac), and ampicillin ( $250 \mathrm{mg} /$ liter; Sigma-Aldrich). After purification on selective media, the isolates were maintained on rye agar plates supplemented with glucose (5 g/liter; Merck), hereafter referred to as RA+, and passaged on potato slices after every fifth to sixth generation of subculturing. Although this study focused on leaf blight, not tuber blight, we host-passaged the $P$. infestans strains on tubers rather than on leaves for better control of the purity of the isolates because this method allows surface sterilization of the host tissues. It also enables the recovery of isolates without, or with only minor contamination by other oomycetes or fungi that need more time than $P$. infestans to pass through the tuber slice.

Sporangia suspensions. Twelve- to fourteen-day-old cultures were scraped off RA+ Phytophthora cultures and suspended in water by vigorous shaking. Sporangia were collected by filtering the suspensions using cloth. Sporangia suspensions were stored in the dark.

Morphological characterization. To analyze the sporangia size, pictures of mature sporangia suspensions were obtained using a microscope camera (Leica). For each isolate, the width and length of 40 sporangia were measured using ImageJ software. The sporangia volume was approximated by calculating the volume bounded by an ellipsoid with equal depth and width $(\mathrm{a}=\mathrm{b}=$ sporangia width; c=sporangia length):

$$
V=\pi a b c \frac{4}{3}
$$

For sporangia production, sporangia of 14-day-old RA+ plates were collected and counted using a Thoma chamber. This experiment was conducted three times with one replicate per isolate. Growth speed was assessed by measuring the area of agar plates covered with mycelium 7 days after the initial inoculation with a mycelium plug.
Mating type. The mating type of the isolates was determined by means of a plate assay. Each isolate was co-inoculated on RA+ plates with two known $P$. infestans strains, one of the A1 (tester strain Syn-5360) mating type and one of A2 (tester strain Syn5393A) mating type (kindly provided by Syngenta, Stein, Switzerland). Two isolates were tested on one plate. The two tester strains Syn-5360 and Syn-5293A were inoculated on opposing sides of the $\mathrm{RA}+$ plates. Two plugs of two isolates of unknown mating types were inoculated between the tester strains, one on each side (Supplementary Fig. S1). To prevent fertilization between the A1 and $\mathrm{A} 2$ tester strains, the central portion of the medium was trumped out with a sterile borer (diameter, $4 \mathrm{~cm}$ ). After approximately 7 days of growth, and when the mycelia of all neighboring strains coalesced, the zones at the contact interface of all isolates were scratched off the plates and diluted in a drop of distilled water on a microscope slide. The slides were screened for the presence of oogonia and/or oospores under the microscope at a magnification of $400 \times$. The zone at the interface of two plugs of the same isolate were scraped off to check for self-mating. The experiment was repeated twice for each isolate. For $\mathrm{CH} 9$, another two repetitions were performed because the first two repetitions were inconclusive.

SSR. Approximately $20 \mathrm{mg}$ of mycelium from 11-day-old RA+ plates was transferred to Eppendorf tubes containing one metal bead (diameter, $3 \mathrm{~mm}$ ). The mycelia were ground in a Retsch Mill for 1 min (frequency, $30 \mathrm{~s}^{-1}$ ). DNA was extracted using the QIAGEN DNeasy Plant kit. DNA quality and concentration were determined using Nanodrop, and the concentration was adjusted if needed. Isolates were then sent to Wageningen University for SSR analysis and multilocus genotype determination (Li et al. 2013).

Fungicide resistance. The sporangial suspension of $P$. infestans strains was prepared as mentioned, except that pea extract-glucose-broth was used instead of water to collect the sporangia from the $P$. infestans grown on RA+. The suspension containing both sporangia and mycelium was filtered through a sieve to remove mycelium; then, it was adjusted to 20,000 sporangia/ml. The mandipropamid and mefenoxam sensitivity test was conducted in 96-well plates amended with $100 \mu \mathrm{l}$ of sterile $0.1 \%$ DMSO with or without the appropriate fungicide concentration. In addition to the negative control without fungicide, the mandipropamid and mefenoxam concentrations tested were 0.01 to $10 \mathrm{ppm}$ and 0.0001 to $100 \mathrm{ppm}$, respectively. Furthermore, $100 \mu \mathrm{l}$ of the sporangia suspension was added to each well. The sensitivity test included four technical replicates. Then, the 96-well plates were incubated in the dark at $19^{\circ} \mathrm{C}$. Fungal growth was assessed by OD measurements 5, 7, and 10 days after incubation using a Biotek plate reader at a wavelength of $405 \mathrm{~nm}$. Grafit 5.0 computer software (Erythacus Ltd.) was used to acquire and process the data. The EC50 (effective concentration of fungicide that reduces $50 \%$ of the fungal growth) was calculated for all monitored isolates and compared with the sensitive reference strains and the mefenoxam without the sensitive reference. No lack of sensitivity to mandipropamid has been monitored so far in natural populations.

Virulence and aggressiveness. The virulence and aggressiveness of $P$. infestans strains were defined as previously reported (Michalska and Sobkowiak 2016). Virulence was assessed on Black's differential set containing potato lineages harboring resistance genes R1, R2, R3, R4, R5, R6, R7, R8, R9, R10, and R11 and cultivars Sarpo Mira and Gasore (kindly provided by JeanLouis Rollot from CRA-W, Gembloux, Belgium). Microplants were cultivated in vitro and multiplied in growth chambers to obtain 40 plantlets per lineage. After $48 \mathrm{~h}$ of acclimation, the plants were planted in the pots containing sterile soil and placed in the greenhouse $\left(20^{\circ} \mathrm{C}, 16\right.$-h light $)$. Simultaneously, 40 plants of cultivar Bintje were planted under greenhouse conditions as an internal control. Leaves were harvested after 7 weeks. Because of differences in growth, the harvesting was spread over 3 days of the seventh week. Leaf discs with a diameter of $2 \mathrm{~cm}$ were cut from the 
third, fourth, and fifth top leaves and placed on water agar (1\%) plates. For each combination of lineage and cultivar, three agar plates each containing five leaf discs of five different plants were prepared. On each leaf disc, $10 \mu \mathrm{l}$ of sporangia suspension was pipetted. Plates were subsequently stored in the dark at $18^{\circ} \mathrm{C}$ in high humidity for 7 days. The plates were photographed using a photo camera (Canon). To evaluate isolate virulence, the number of symptomatic leaf discs was counted manually for each combination of factors. If $>10$ discs were infected, then the gene-gene interaction was defined as compatible. If fewer than five discs were infected, then the interaction was described as incompatible. All cases in between were marked as undefined. To quantify the severity of infection and, thus isolate aggressiveness, an estimate of the surface covered with mycelium was computed using a macro-instruction in ImageJ software (Guyer et al. 2015).

To confirm the validity of the high-throughput leaf disc assay, isolate virulence was assessed on leaflets and on leaf discs for five isolates. In addition to the 15 leaf discs, five leaflets of all lineages of Black's differential set and of plants of cultivar Bintje were inoculated with sporangia suspensions of $\mathrm{CH} 2, \mathrm{CH} 6 \mathrm{~b}, \mathrm{CH} 15$, $\mathrm{CH} 16 \mathrm{a}$, and Rec01. After 7 days, the infected leaf discs and leaflets were counted. A hierarchical clustered dendrogram was constructed based on these results for both infection methods, and the dendograms were then compared by means of a tanglegram and computation of an entanglement factor (0.52) and Baker's gamma association index (0.99) (Baker 1974). The tanglegram showed similar clustering of the isolates (Supplementary Fig. S2). The entanglement factor (characterizing the alignment quality) was between 0 and 1, whereas Baker's gamma index (a measure of similarity) was between -1 and 1 . A low value for the first index and a value close to 1 for the second index indicated significant similarity between the two dendograms, suggesting similar and comparable results for both methods, thus validating the use of the high-throughput leaf disc assay for virulence characterization.

Bacterial antagonists. Antagonism experiments were conducted with three Pseudomonas strains isolated from the potato rhizosphere (R47, R76) and phyllosphere (S19) (Hunziker et al. 2015). Bacterial strains were grown on Luria Broth (LB) medium (Lennox, Applichem Panreac). Whenever bacterial suspensions were needed, overnight cell cultures grown on LB agar plates were suspended in $\mathrm{NaCl}(0.9 \%)$ to reach an $\mathrm{OD}_{570}$ of 1 .

In vitro sensitivity to bacterial antagonists. To determine the effects on mycelial growth, 5-mm plugs of $P$. infestans isolates were inoculated on the center of RA+ plates. Three droplets of $10 \mu \mathrm{l}$ of bacterial suspensions were then placed at the border of the plates. This was performed on three replicate plates. The Petri dishes were incubated at $18^{\circ} \mathrm{C}$ for 6 days and then photographed. For logistic reasons, the experiment was spread over 2 days and Rec01 was included on both days as an internal control. Inhibition of mycelial growth was assessed by measuring the growth area of the isolates using the measuring tool of ImageJ. To perform comparisons between experiments and between isolates, data were expressed as a percentage of corresponding controls. For sporangia germination, droplets of $10 \mu \mathrm{l}$ of a mixture of bacterial suspensions $\left(\mathrm{OD}_{570}=1\right)$ and sporangia suspensions $(100,000$ sporangia/ml $)$ were spotted on water agar $(1 \%)$ plates and incubated in the dark at $18^{\circ} \mathrm{C}$. Pictures were obtained after $24 \mathrm{~h}$ using a binocular camera (Leica). Numbers of germinated sporangia and atypically germinated sporangia were counted using the cell counter tool of ImageJ. On the pictures, germ tubes were highlighted in red with MS Paint, and the mean germ tube length was estimated using a macro-instruction in ImageJ.

In vivo sensitivity to bacterial antagonists. Five $P$. infestans isolates were selected for an infection assay on potato cultivar Bintje. The method used was identical to the aforementioned leaf disc assay. For each combination of bacterial strain and $P$. infestans isolate, three plates of five leaf discs were prepared. Bacterial suspensions $\left(\mathrm{OD}_{570}=1\right)$ were added to the sporangia suspensions immediately before inoculation.
Statistical analysis. All data were analyzed using R software. One-way and two-way analyses of variance (ANOVA) were performed using the data or the transformed data (log, boxcox) from the virulence and inhibition assays when assumptions for normality and homoscadiscity were met. If heteroscadiscity was established, then a white-adjusted ANOVA procedure was used. In the case of violation of the assumption of normality, the nonparametric Kruskal Wallis test was used. A comparison of the means was performed according to the test. Packages used included agricolae, car, and MASS. For the dual assay on Petri dishes, Dunnett's test for comparison of means was performed per isolate. The principal component analysis was computed using the FactoMineR and FactoExtra packages. For the correlation analysis, Pearson's correlation coefficients were calculated if assumptions for linear covariation and normality were met; if they were not met, then Kendall's or Spearman's methods were used. For the tanglegram constructed for the comparison between leaflet and leaf disc assays, the dendextend package was used.

\section{RESULTS}

Isolation of $\boldsymbol{P}$. infestans strains. In 2015, 60 outbreaks of late blight were reported to the decision support system PhytoPRE in Switzerland (Musa-Steenblock and Forrer 2005). A total of 19 isolates were successfully retrieved and purified from 10 different potato cultivars and from 16 distinct locations. Two isolates, $\mathrm{CH} 1$ and $\mathrm{CH} 2$, were isolated from Western Switzerland; isolates $\mathrm{CH} 3$ to $\mathrm{CH} 11$ were collected in central Switzerland; isolates $\mathrm{CH} 12$ to $\mathrm{CH} 14$ were collected in Northeastern Switzerland; and isolates CH15 and CH16 were collected in Eastern Switzerland (Fig. 1). At two locations, sampling was performed at two and three different timepoints, yielding isolates $\mathrm{CH} 6 \mathrm{a}, \mathrm{CH} 6 \mathrm{~b}, \mathrm{CH} 6 \mathrm{c}$ and $\mathrm{CH} 16 \mathrm{a}$, $\mathrm{CH} 16 b$, respectively. $\mathrm{CH} 1, \mathrm{CH} 6 \mathrm{a}, \mathrm{CH} 12, \mathrm{CH} 13, \mathrm{CH} 14, \mathrm{CH} 15$, and $\mathrm{CH} 16 \mathrm{a}$ were described as primary infections.

Multilocus genotype determination. SSR genotyping classified 13 of 19 isolates as Blue13 and six isolates as miscellaneous, with the latter being isolated from Northeastern and Eastern Switzerland (Fig. 1). Altogether, 41 alleles were detected at 12 loci (Supplementary Table S1). All loci were polymorphic with three alleles in most cases, except for SSR8 and SSR2 of Pi63 and Pi70, for which only two were found, and G11 and D13, for which eight and seven, respectively, were identified. At locus G11, the highest diversity was observed for the Northeastern and Eastern isolates. In contrast, for locus D13, the highest diversity was found within the Blue13 (EU_13_A2) genotypes. For two isolates, $\mathrm{CH} 12$ and $\mathrm{CH} 13$, two different profiles were obtained. Of the miscellaneous isolates, $\mathrm{CH} 15$ and $\mathrm{CH} 14$ were of mating type A1. Furthermore, isolates $\mathrm{CH} 6 \mathrm{a}, \mathrm{CH} 6 \mathrm{~b}$, and $\mathrm{CH} 6 \mathrm{c}$, which were isolated from the same field and characterized as Blue13 isolates, differed in two loci. CH6b had a third allele at locus SSR4, whereas CH6c displayed trisomy at locus D13 and locus SSR4. Isolates $\mathrm{CH} 16 \mathrm{a}$ and $\mathrm{CH} 16 \mathrm{~b}$ had identical allelic profiles. A minimum spanning network based on Bruvo's distance identified one main Blue13 branch comprising at its center four isolates sharing the same allelic profile, namely, $\mathrm{CH} 2$, $\mathrm{CH} 3, \mathrm{CH} 6 \mathrm{a}$, and $\mathrm{CH} 7$, which were isolated from central Switzerland (Fig. 2A). Isolates CH4, CH9, CH10, CH11, CH5, CH1, CH6b, $\mathrm{CH} 6 \mathrm{c}, \mathrm{CH} 8$, and Rec01 were grouped on the same branch. Miscellaneous isolates from Northeastern and Eastern Switzerland formed three distinct side branches, among which one contained CH15, CH16a, CH16b, and CH13.

Phenotypical characterization. In vitro assessment of sporangia production, size, and radial growth speed revealed considerable differences among isolates (Fig. 1, Supplementary Table S2). Radial growth ranged from 134 to $548 \mathrm{~mm}^{2}$ per day on $\mathrm{RA}+$. Sporangia yields of 14-day-old cultures on RA+ ranged from an average of 7638 sporangia to 651,666 sporangia per plate. However, for some isolates, among which the most productive were $\mathrm{CH} 12, \mathrm{CH} 15, \mathrm{CH} 16 \mathrm{a}, \mathrm{CH} 16 \mathrm{~b}$, and $\mathrm{CH} 8$, high variability in sporangia 
production was observed. Sporangia volumes varied between 6314 and $11,275 \mu \mathrm{m}^{3}$.

Fungicide resistance. None of the isolates was resistant to mandipropamid (data not shown). Seven isolates, CH3, CH4, CH5, $\mathrm{CH} 6 \mathrm{~b}, \mathrm{CH} 6 \mathrm{c}, \mathrm{CH} 11$, and $\mathrm{Rec01}$ were resistant to mefenoxam. Isolates $\mathrm{CH} 2, \mathrm{CH} 7, \mathrm{Ch} 8, \mathrm{CH} 9, \mathrm{CH} 10$, and $\mathrm{CH} 16 \mathrm{~b}$ showed intermediate resistance (Fig. 1). Most resistant isolates were found in central Switzerland, and all were of mating type A2.

Virulence, race determination, and pathogen aggressiveness. To characterize and compare the isolates' potency to infect potato plants, virulence and aggressiveness were analyzed. Virulence was defined as the ability or inability of $P$. infestans isolates to infect plants carrying resistance genes (Michalska and Sobkowiak 2016; Niks et al. 2019). Pathogen aggressiveness expresses the quantitative assessment of disease symptoms on a susceptible potato cultivar. To determine isolate virulence, an infection assay was conducted for all 11 R-gene lineages of Black's differential set (Fig. 3A). Sarpo Mira (SM) and Gasore (GAS) were included as resistant cultivars, and R0 and Bintje (BIN) were included as susceptible lineages and cultivars. For each combination of isolate and lineage, the number of successful infections on 15 leaf discs was counted. CH6b and CH6c showed the highest number of compatible gene-gene interactions (10), followed by CH8 (8) and CH12 (7) (Fig. 3C). All those isolates also successfully infected Sarpo Mira and Gasore, but less than on Bintje or R0. Pathogen aggressiveness was assessed by evaluating infection severity on Bintje (Fig. 3B). Furthermore, $\mathrm{CH6b}$ and $\mathrm{CH6c}$ were of virulence race 1.2.3.4.5.6.8.10.11, and both were slightly more aggressive on Bintje than CH6a, which was of race 1.6.7.11 (Fig. 3B and C). $\mathrm{CH} 16 \mathrm{a}$ and $\mathrm{CH} 16 \mathrm{~b}$ exhibited identical virulence races but differed in their aggressiveness on Bintje (Fig. 3B and C). CH6b and CH6c were able to overcome all R-genes in the set, including Sarpo Mira

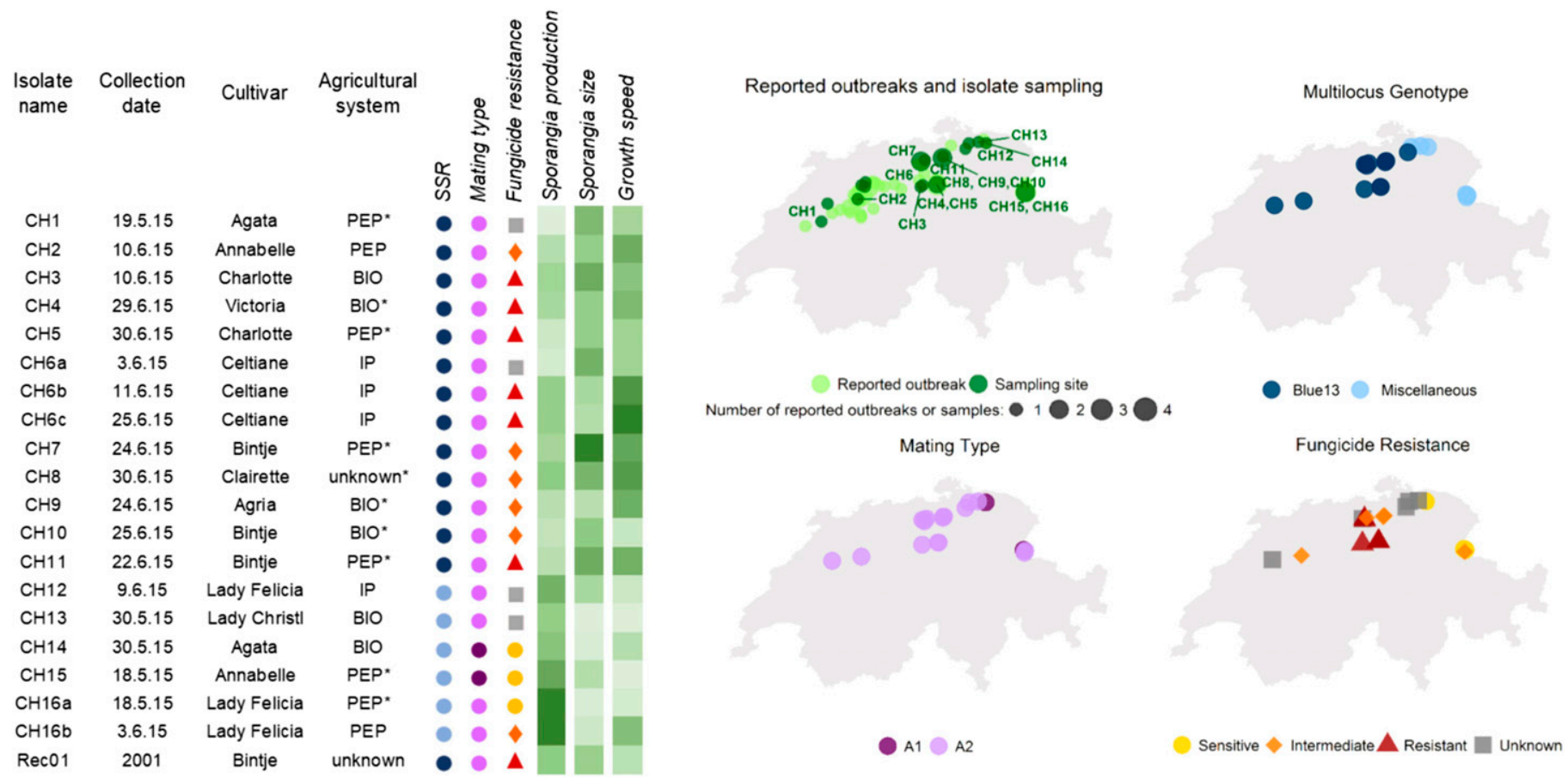

Fig. 1. Names, collection date, cultivar, agricultural system (PEP: proof of ecological performance; IP: integrated pest management; BIO: organic farming), and genetic and phenotypic characteristics of the collected isolates. Values for sporangia production, sporangia size, and growth speed range from high values in dark green to low values in light green (see Supplementary Table S2 for raw data). Geographical distribution of the outbreaks and collection of isolates as well as the distribution of multilocus genotype, mating type, and resistance to the fungicide mefenoxam are represented on maps.

A
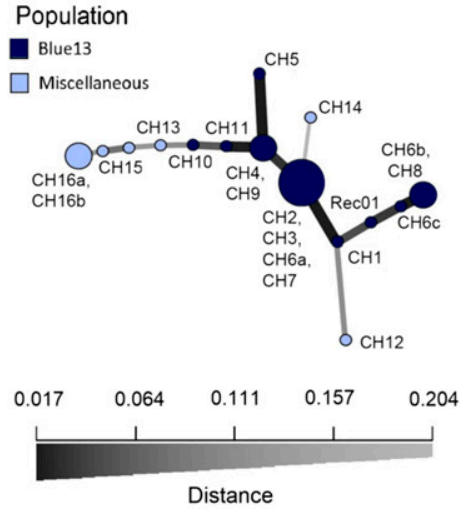

B

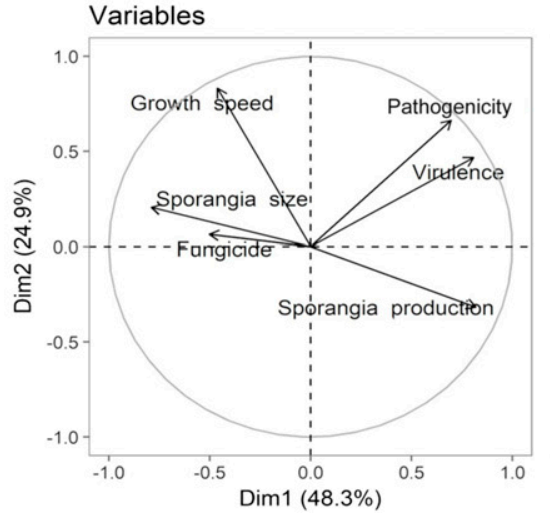

Individuals

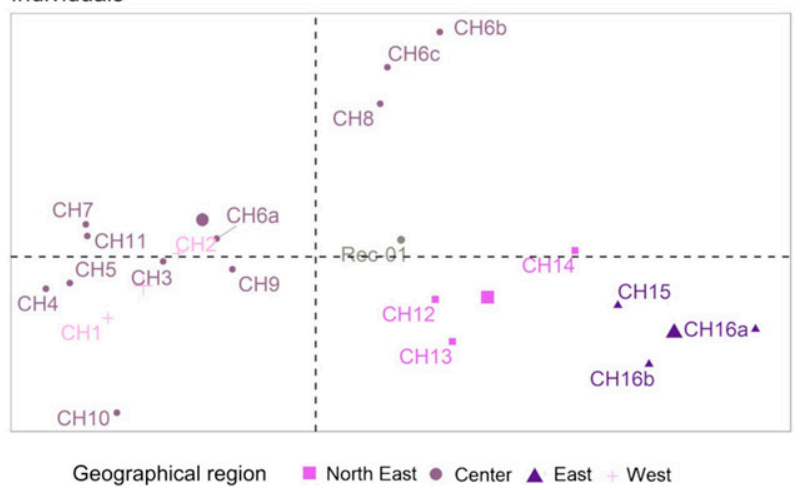

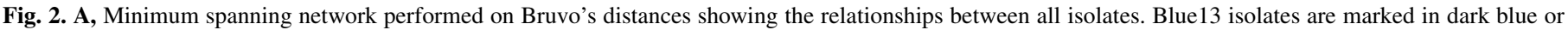

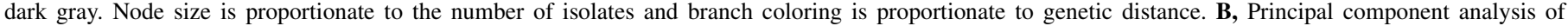
morphological traits, virulence, pathogenicity, and fungicide resistance. Rec01 was included in the analysis as a supplementary individual. 
and Gasore. A1 mating type isolates $\mathrm{CH} 14$ and $\mathrm{CH} 15$ showed similar virulence profiles and were among the most aggressive strains. Virulence against R1, R7, R10, and R11 was observed in most cases, in contrast to R2, R5, R6, and R8, for which few compatible interactions were found. For R9, no compatible interaction was found. However, the R9 lineage plants developed unknown leaf symptoms days before the experiment; therefore, the results should be interpreted with great care. The principal component analysis revealed that the most virulent and aggressive isolates were mainly found in Northeastern and Eastern Switzerland (Fig. 2B). Two groups can be distinguished when looking at the six most virulent and aggressive strains: $\mathrm{CH} 6 \mathrm{~b}$ and $\mathrm{CH} 6 \mathrm{c}$. $\mathrm{CH} 6 \mathrm{~b}$ and

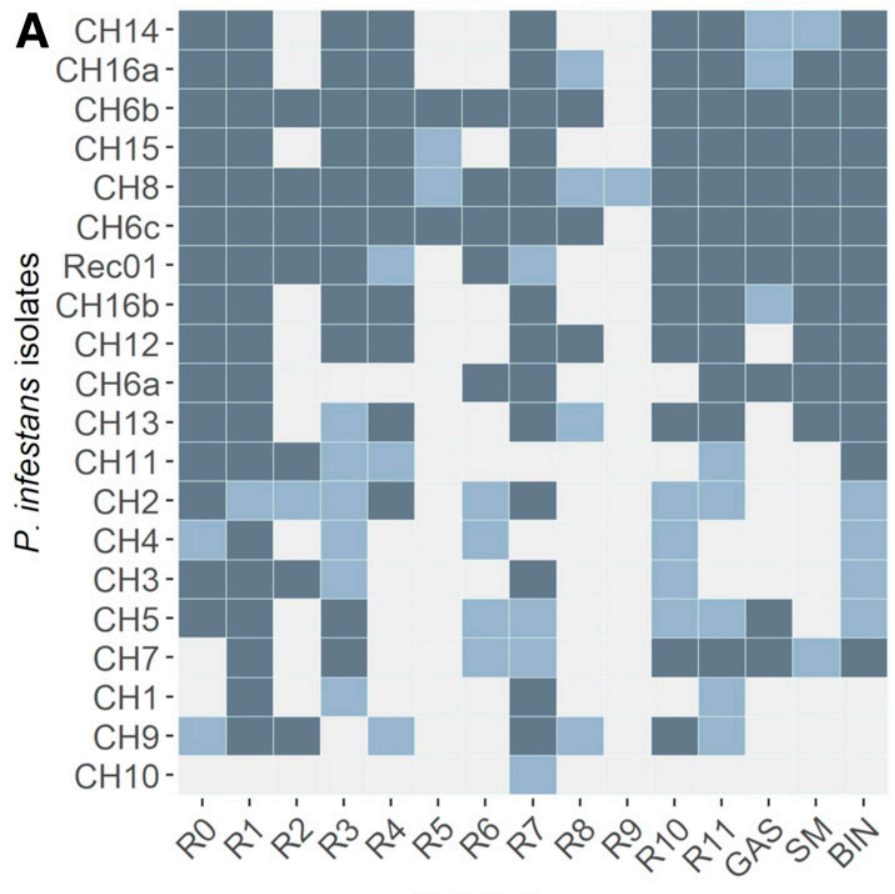

Potato lineages

Gene for gene interaction:

Compatible Incompatible Undefined

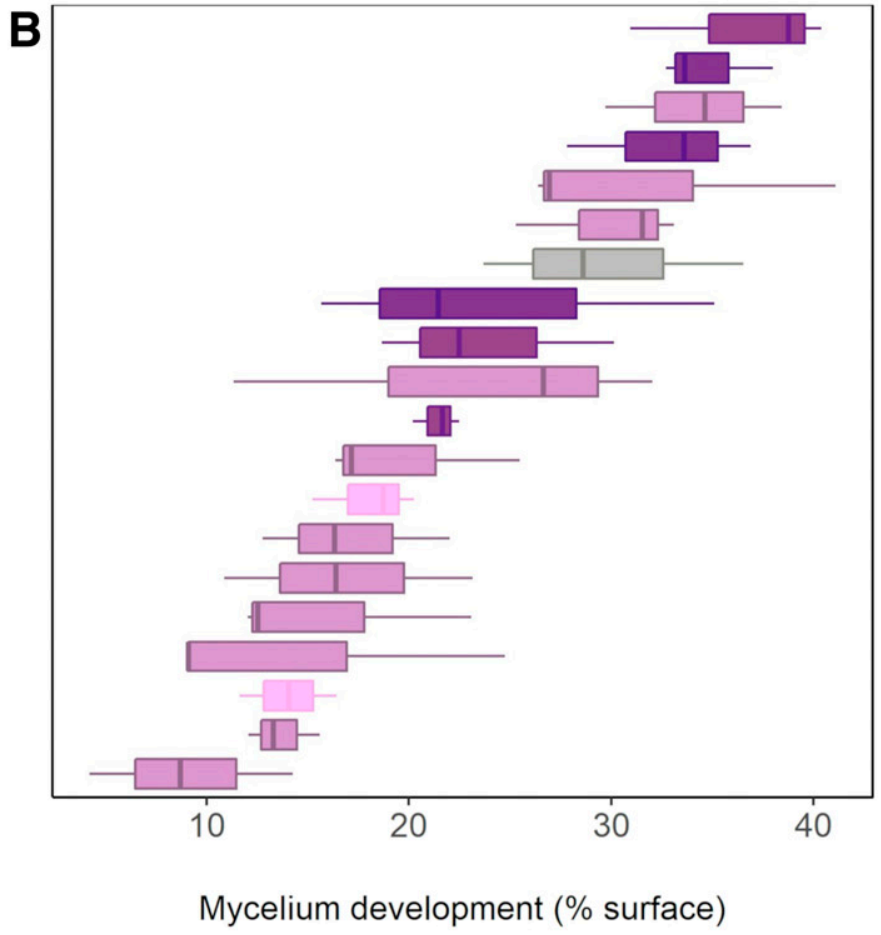

Geographical region:

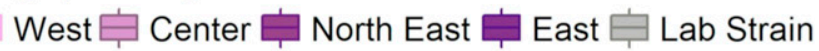

C

Origin

1.2.3.4.5.6.7.8.10.11

1.2.3.4.6.7.10.11

1.3.4.7.8.10.11

1.2.3.6.10.11

1.3.4.7.10.11

1.4.7.10.11

1.3.10.11

1.2.7.10

1.6.7.11

1.2 .7

1.2

1.3

1.7

4.7

1

7
$\mathrm{CH} 6 \mathrm{~b}, \mathrm{CH} 6 \mathrm{c}$

$\mathrm{CH} 8$

CH12

Rec01

CH14, CH15, CH16a, CH16b

$\mathrm{CH} 13$

$\mathrm{CH} 7$

$\mathrm{CH} 9$

$\mathrm{CH} 6 \mathrm{a}$

$\mathrm{CH} 3$

$\mathrm{CH} 11$

$\mathrm{CH} 5$

CH1

$\mathrm{CH} 2$

$\mathrm{CH} 4$

$\mathrm{CH} 10$

\section{Centre}

Centre

North East

Centre

North East and East

North East

Centre

Centre

Centre

Centre

Centre

Centre

West

West

Centre

Fig. 3. Virulence and pathogen aggressiveness profiles. A, The heatmap represents incompatible (number of infected discs <5) and compatible (number of infected discs $>10$ ) relationships between Phytophthora infestans isolates and potato lineages harboring different resistance genes. Gasore (GAS) and Sarpo Mira (SM) were included as so-called resistant cultivars, and Bintje (BIN) was included as a susceptible cultivar. The relationship was characterized as undefined if no conclusion could be drawn $(5<$ number of infected discs $<10)$. B, The aggressiveness of the strains was assessed on cultivar Bintje on leaf discs and characterized by the surface covered with mycelium. C, Virulence races for all $P$. infestans isolates. 
CH6c are average sporangia producers of averaged-size sporangia, but they show fast radial growth in vitro. $\mathrm{CH} 15, \mathrm{CH} 16 \mathrm{a}, \mathrm{CH} 16 \mathrm{~b}$, and $\mathrm{CH} 14$ produce high numbers of small sporangia and show slow radial growth.

Growth inhibition by bacterial antagonists. In a growth inhibition assay on RA+ plates, all P. infestans isolates were coinoculated with each of the three Pseudomonas strains. The experiment was divided in two batches, and Rec01 was included in both as an internal control. Because there was no significant difference in growth or inhibition between the two batches of Rec01, they were treated as one set. All isolates were very strongly inhibited by strain $\mathrm{R} 47$, which reduced their radial growth to as low as 1 to $15 \%$ of the unexposed control growth. Results for S19 and R76 were much more variable, with inhibition rates ranging from 12 to $67 \%$ for S19 and from 17 to $92 \%$ for R76 (Fig. 4). CH11 and $\mathrm{CH} 13$ were strongly inhibited by all bacterial strains. For S19, isolates $\mathrm{CH} 1$ to $\mathrm{CH} 5$ and $\mathrm{CH} 7$ to $\mathrm{CH} 10$ showed strong to intermediate inhibition; $\mathrm{CH} 15, \mathrm{CH} 16 \mathrm{a}$, and $\mathrm{CH} 16 \mathrm{~b}$ showed intermediate inhibition; and $\mathrm{CH} 12$ and $\mathrm{CH} 14$ showed very low susceptibility. For R76, isolates CH6a, CH6c, CH12, CH15, and $\mathrm{CH} 16$ a were not significantly inhibited. The other $P$. infestans isolates showed intermediate inhibition (Fig. 4). Effects of the strains over time were compared to observe radially expanding isolates $\mathrm{CH} 3, \mathrm{CH} 9$, and Rec01 and isolates $\mathrm{CH} 15, \mathrm{CH} 16 \mathrm{a}, \mathrm{CH} 16 \mathrm{~b}$ (Fig. 5). Radial expansion followed a regular thread over time for all isolates when exposed to R76. For S19, radial expansion almost came to a halt between days 7 and 8 . For R47, radial growth was very limited overall. Interestingly, $\mathrm{CH} 3$ and $\mathrm{CH} 9$ reacted very similarly to R76 and S19, whereas Rec01, CH15, CH16a, and $\mathrm{CH} 16 \mathrm{~b}$ were inhibited by S19, but not by R76. The shape and morphology of the mycelia were affected in different ways. The mycelium of isolates $\mathrm{CH} 3$ and $\mathrm{CH} 9$ was less dense, especially in periphery. The mycelium of $\mathrm{CH} 16 \mathrm{a}$ and $\mathrm{CH} 16 \mathrm{~b}$ exposed to $\mathrm{S} 19$ appeared denser in comparison with the untreated mycelium. The

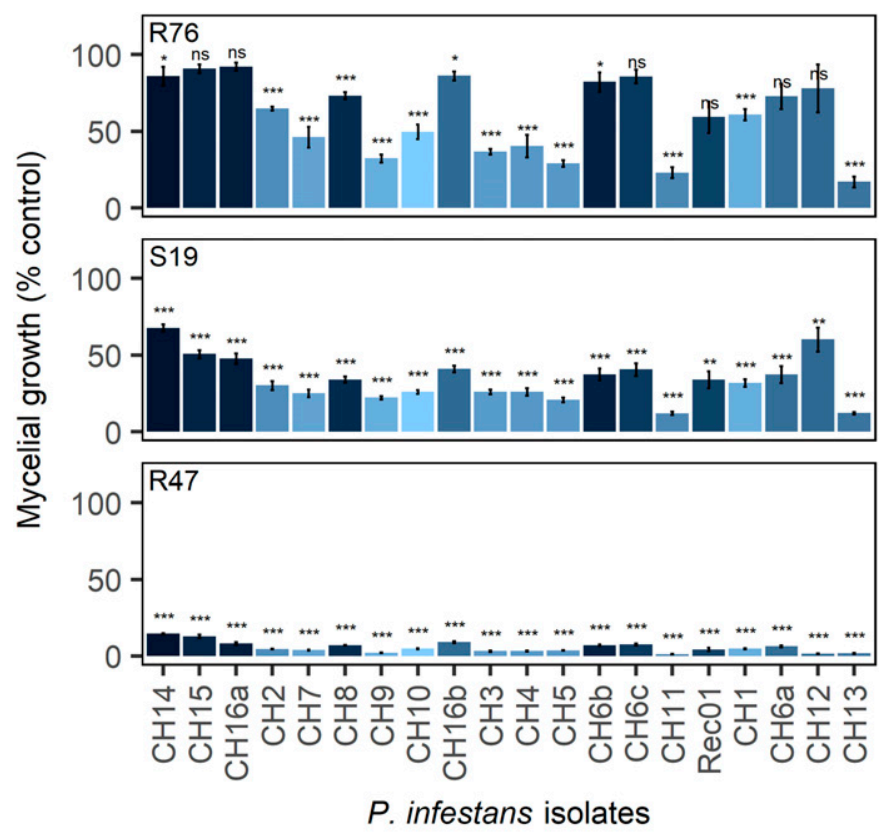

Virulence: 101520253035

Fig. 4. Inhibition of growth of Phytophthora infestans isolates in the presence of antagonistic bacteria. Mycelium growth is expressed as the percentage of the growth of nonexposed isolates (control plates) corresponding to $100 \%$ after 8 days of incubation. All treatments were compared with corresponding control plates in such a way that Dunnett's test for the comparison of means was performed after analysis of variance for each isolate separately. mycelium of $\mathrm{CH} 3$ and $\mathrm{CH} 9$, and to a lesser extent Rec01, exhibited clear-cut triangular inhibition zones. In contrast, mycelia of isolates $\mathrm{CH} 16 \mathrm{a}, \mathrm{CH} 16 \mathrm{~b}$, and $\mathrm{CH} 15$ grew radially. It seemed that the isolates reacted slightly differently to R76 (Fig. 5). The same set of isolates was challenged by each of the three bacterial strains in a leaf disc assay. For $\mathrm{CH} 3$, Rec01, $\mathrm{CH} 16 \mathrm{a}$, and $\mathrm{CH} 16 \mathrm{~b}$, all three bacterial strains significantly inhibited symptom development and mycelial growth (Fig. 6). CH9 and $\mathrm{CH} 15$ were significantly inhibited by $\mathrm{S} 19$ and $\mathrm{R} 47$, respectively.

To determine whether the bacteria act as mere growth inhibitors or are able to kill $P$. infestans, and whether repeated exposure to the same bacterial strain would lead to lower (adaptation) or higher sensitivity of the P. infestans isolates, four isolates (CH6b, CH6c, $\mathrm{CH} 15$, and Rec01) were exposed twice to the three bacterial strains. Between the two rounds of exposure, the isolates were incubated on RA+ alone for recovery. The ANOVA revealed interactions between the bacterial strains and the isolates after the exposure round. The data were analyzed separately for each strain and isolate, and the first exposure, recovery, and second exposure were compared. None of the isolates exposed to R47 recovered after the first exposure (Fig. 7). For S19, similar inhibition rates were obtained for the two rounds of exposure, except for Rec01, which became highly susceptible to this strain during the second exposure. Interestingly, after the first exposure to S19, CH6c did not recover fully, but $\mathrm{CH} 15$ grew larger than the unexposed control. These isolates were inhibited again to the same extent during the second exposure. For R76, the ANOVA did not reveal any interaction between the isolate and treatment, suggesting an overall common response of the isolates to this bacterial strain. None of the isolates fully recovered after the first exposure to R76, except for CH15. A separate ANOVA for each isolate revealed that the second exposure with this strain led to significantly higher inhibition for $\mathrm{CH} 15$ and Rec01 in comparison with the first exposure.

Correlation analysis. Sporangia production and size were negatively correlated to one another $(\mathrm{R}=-0.58 ; P=0.0068)$, as were sporangia size and growth speed $(\mathrm{R}=-0.56 ; P=0.01)$ (Table 1). Virulence and aggressiveness were strongly correlated $(\mathrm{R}=0.82 ; P<0.001)$, whereas aggressiveness was negatively correlated to sporangia size $(\mathrm{R}=-0.50 ; P=0.024)$ and positively correlated to sporangia production $(\mathrm{R}=0.46 ; P=0.04)$. There was no correlation between radial growth and virulence or aggressiveness. Susceptibility to R76, R47, and S19 was negatively correlated with virulence $(\mathrm{R}=-0.69$ and $P=0.00084 ; \mathrm{R}=-0.68$ and $P=$ $0.00091 ; \mathrm{R}=-0.62$ and $P=0.0032$, respectively) (Table 1 ). Pathogen aggressiveness was negatively correlated with susceptibility to $\mathrm{R} 76(\mathrm{R}=-0.55 ; P=0.012)$.

\section{DISCUSSION}

During the course of previous studies aiming at developing microbe-based solutions to control potato late blight, we isolated bacterial strains from the rhizosphere and phyllosphere of potato plants and characterized their inhibitory activity against the oomycete $P$. infestans (De Vrieze et al. 2015, 2018; Guyer et al. 2015; Hunziker et al. 2015). However, these studies were based on a single $P$. infestans strain (Rec01) isolated in 2001, which had unknown representativity in terms of recent epidemiology, virulence, and sensitivity to fungicides. To determine the range of efficacy of our biocontrol candidates for relevant $P$. infestans strains currently causing infections, we performed a $P$. infestans collection survey throughout Switzerland in 2015 and retrieved 19 P. infestans isolates from 11 different cultivars in 16 different locations. Multilocus genotype data suggested domination of genotype Blue13 in Western and central Switzerland. As in France, the United Kingdom, and the Netherlands (Cooke et al. 2012; Gisi et al. 2011; Li et al. 2012), the highly aggressive Blue13 genotype was previously reported to have displaced the previously dominant A1 population (Gisi et al. 2011) (Fig. 1). However, in the past 5 years, 
three new genotypes, EU_37_A2 (a genotype that is insensitive to the fungicide fluazinam), EU_41_A2, and EU_36_A2, have emerged in different parts of Europe and were reported to be displacing current Blue13 (EU_13_A2) populations, but none of those isolates was found in 2015 (Fig. 1). Interestingly, our original strain Rec01, isolated in 2001, was also characterized as Blue13, but the first report of Blue13 occurred in 2004 in the Netherlands and Germany (Cooke et al. 2012).
We observed high variability in virulence and aggressiveness among the 13 Blue 13 isolates (Fig. 3 ). High phenotypical variability has been reported for asexually reproducing lineages through mutation and other mechanisms, such as gene conversion or mitotic crossing-over (Samen et al. 2003). Gisi et al. (2011) suggested that if the genetic diversity in a clonal population is high enough, then asexually reproducing populations can successfully and rapidly adapt to new conditions. P. infestans strains $\mathrm{CH} 6 \mathrm{a}, \mathrm{CH} 6 \mathrm{~b}$, and
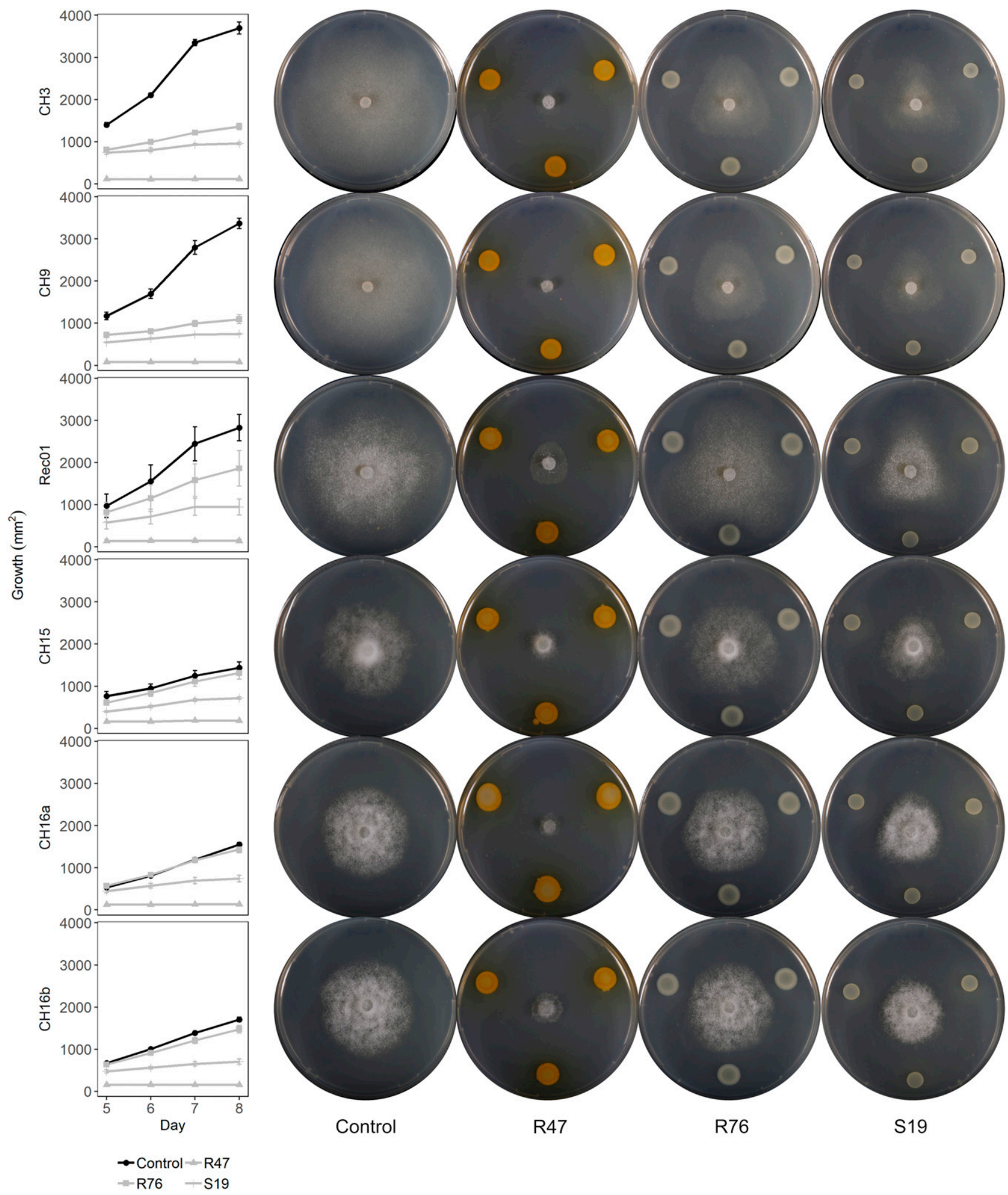

Fig. 5. Evolution over time of the growth of three fast-growing and three slow-growing Phytophthora infestans isolates when exposed to three different bacterial strains. 
CH6c, which were isolated from the same field at different time points, are an interesting case in this regard: although all are classified as Blue13, these three isolates have distinct allelic profiles and differ in virulence and aggressiveness (Fig. 3). Similarly, $\mathrm{CH} 16 \mathrm{a}$ and $\mathrm{CH} 16 \mathrm{~b}$ differed in resistance to the fungicide mefenoxam and in aggressiveness, although they belonged to the same virulence race (Figs. 1 and $3 \mathrm{C}$ ). $\mathrm{CH} 16 \mathrm{a}$ was isolated prior to any fungicide application; however, $\mathrm{CH} 16 \mathrm{~b}$ was isolated 2 weeks later and 3 days after the crop was treated with propamocarb-hydrochlorid and fluopicolide. Use of phenylamines was not reported in this field, but we cannot exclude that human intervention in and around this site to control late blight spearheaded the booming of these less virulent and less sensitive genotypes. Interestingly, most mefenoxamresistant strains were isolated from mid-June, whereas the mefenoxamsensitive strains were isolated earlier. $\mathrm{CH} 2$, which showed intermediate resistance to mefenoxam, originated from a field where mefenoxam had been used in combination with fluazinam. Mandipropamid, cymoxanil, and the combination of propamocarb-hydrochlorid and

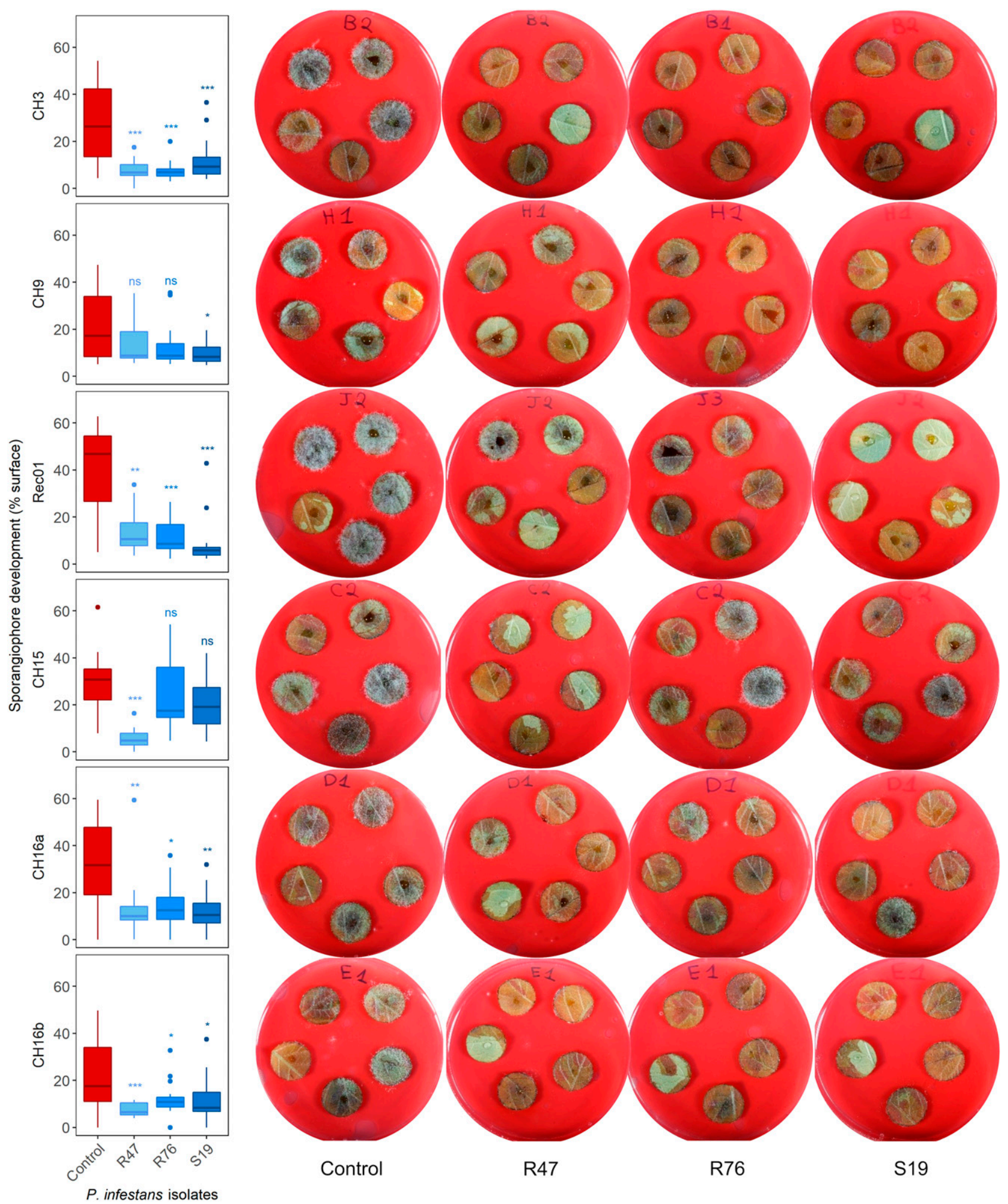

Fig. 6. Effect of bacterial antagonists R76, S19, and R47 on sporangiophore development on leaf discs. 
fluopicolide were also reportedly used for that field. Furthermore, CH6a, CH6b, and CH6c withstood several fungicide applications. CH6a was isolated 6 days after the first treatment with propamocarbhydrochlorid and fenamidone, which was later alternated with fluazinam and chlorothalonil, when $\mathrm{CH} 6 \mathrm{~b}$ and $\mathrm{CH} 6 \mathrm{c}$ were isolated. Although the infection intensity was described as low when CH6a was isolated ( $<5 \%$ of infected plants), it was much higher when $\mathrm{CH} 6 \mathrm{~b}$ and $\mathrm{CH} 6 \mathrm{C}$ were isolated (5 to $25 \%$ of infected plants). Both $\mathrm{CH} 6 \mathrm{~b}$ and $\mathrm{CH} 6 \mathrm{c}$ are resistant to mefenoxam, but these findings raised the question of whether $\mathrm{CH} 6 \mathrm{~b}$ and $\mathrm{CH} 6 \mathrm{c}$ developed partial resistance to fluazinam, similarly to EU_37_A2, or to any of the other active substance used.

Overall, the miscellaneous isolates were both more aggressive and virulent than the Blue13 isolates (Fig. 3). Interestingly, CH14, $\mathrm{CH} 15, \mathrm{CH} 16 \mathrm{a}$, and $\mathrm{CH} 16 \mathrm{~b}$ were all of race 1.3.4.7.10.11, which was the most encountered race in France, Norway, Finland, and Switzerland, but not in Germany, in the 1990s (Hermansen et al. 2000). This raises the question of whether in this particularly isolated region the population has remained relatively stable since then. All four strains were highly virulent and isolated from Eastern and Northeastern Switzerland and might have been too remote to be displaced. These isolates were also highly aggressive on Bintje, and their levels of infection were matched only by one Blue 13 isolate. The presence of different miscellaneous genotypes and the presence of both mating types hint at the potential occurrence of sexual reproduction. However, the sole presence of both mating types is a necessary, albeit not sufficient, condition for sexual reproduction to occur (Yuen and Andersson 2013). Despite co-occurrence of both mating types in Europe, the United States, and Asia since the late 1970s, and although they have become more diverse, most populations of $P$. infestans have remained clonal (Brurberg et al. 2011; Chowdappa et al. 2015; Cooke et al. 2012; Fry et al. 2013; Gisi et al. 2011; Hu et al. 2012; Li et al. 2012; Li et al. 2013; Montarry et al. 2010; Montes et al. 2016), with the exceptions of $P$. infestans's center of origin in Mexico and, more recently, the Nordic countries, the Netherlands, Poland, and Estonia (Brurberg et al. 2011; Brylińska et al. 2016; Chmielarz et al. 2014; Kiiker et al. 2018; Sjöholm et al. 2013; Widmark et al. 2007). In these European countries, SSR genotyping revealed highly variable genotypic profiles and high numbers of distinct multilocus genotypes. Moderately virulent isolates $\mathrm{CH} 12$ and $\mathrm{CH} 13$ might, for instance, have originated from oospores in the soil (Fig. 3). The highest allelic diversity was observed for loci D13 and G11, but the number of isolates sampled was too low to allow accurate estimations of genotypic diversity, allelic diversity, and Hardy Weinberg equilibrium of the alleles, which would provide higher resolution insight on the genotypic structure of the present population. Without intensive monitoring and genotyping coupled to isolation of oospores from infected leaves or soil, there is no conclusive proof of recent or past sexual reproduction events in these regions (Gisi et al. 2011; Yuen and Andersson 2013).

Notable phenotypical differences between all isolates were observed for sporangia production, sporangia size, and radial growth speed on rye agar (Fig. 1). Our data suggest that isolates producing high numbers of sporangia had smaller sporangia in comparison with less productive ones. Moreover, a negative correlation between growth speed and sporangia production was observed, suggesting that isolates producing many sporangia tended to have less radial spread on agar plates than the less productive isolates. In general, the most virulent isolates were also the most aggressive ones and the ones producing the highest numbers of (small) sporangia. However, because leaf discs were inoculated with the same numbers of sporangia for all isolates, it is suggested that the small sporangia of these prolific isolates were more infectious than the larger sporangia of the less prolific isolates.

During previous studies, we evaluated the potential use of potatoassociated Pseudomonas strains as biocontrol agents against late blight on Blue13 isolate Rec01 (De Vrieze et al. 2015; De Vrieze et al. 2018; Guyer et al. 2015; Hunziker et al. 2015). We selected three bacterial strains with varying activity against Rec 01 and tested them for in vitro growth inhibition of all $P$. infestans isolates collected for the present study. When exposed to the most active Pseudomonas, strain R47, strong inhibition of mycelial growth was observed for all P. infestans isolates (Fig. 4). However, when facing less active strains such as S19 or R76, high variability was observed between the different $P$. infestans isolates. In particular, a negative correlation between virulence and inhibition of in vitro growth highlighted that the most virulent isolates were the least inhibited, particularly when exposed to R76. The grouping of isolates according to the function of susceptibility revealed different groups for each bacterial strain. In parallel, the differences in morphology of the inhibited mycelia (i.e., shape and density of the oomycete growth on the plate) (Fig. 5) suggested that different isolates of $P$. infestans react in different ways to exposure to Pseudomonas

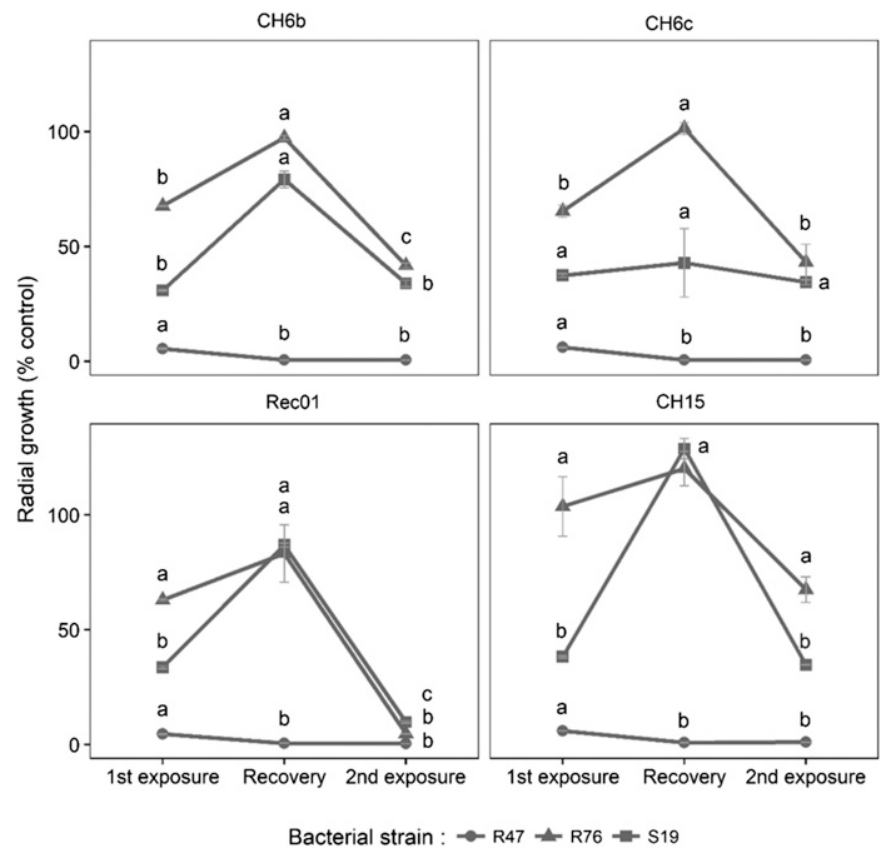

Fig. 7. Effects on mycelial growth of repeated exposure to bacterial antagonists R76, S19, and R47.

TABLE 1. Correlations between morphological traits, virulence, and pathogen aggressiveness of Phytophthora infestans isolates and correlations between susceptibility to bacterial strains R47, S19, and R76 and virulence and pathogen aggressiveness of $P$. infestans isolates ${ }^{\mathrm{a}}$

\begin{tabular}{lcc}
\hline & $\begin{array}{c}\text { Correlation } \\
\text { coefficient }\end{array}$ & $P$ \\
\hline Traits & $\mathbf{0 . 8 2}$ & $\mathbf{< 0 . 0 0 0 1}$ \\
Virulence and aggressiveness & $\mathbf{0 . 4 8}$ & $\mathbf{0 . 0 3 2}$ \\
Sporangia size versus growth speed & $\mathbf{0 . 4 6}$ & $\mathbf{0 . 0 4}$ \\
Sporangia production versus virulence & 0.35 & 0.13 \\
Sporangia production versus aggressiveness & 0.17 & 0.47 \\
Growth speed versus aggressiveness & -0.06 & 0.79 \\
Growth speed versus virulence & -0.39 & 0.091 \\
Sporangia size versus aggressiveness & $\mathbf{- 0 . 5 0}$ & $\mathbf{0 . 0 2 4}$ \\
Sporangia size versus virulence & $-\mathbf{0 . 5 6}$ & $\mathbf{0 . 0 1}$ \\
Sporangia production versus growth speed & $\mathbf{- 0 . 5 8}$ & $\mathbf{0 . 0 0 6 8}$ \\
Sporangia production versus sporangia size & & \\
Susceptibility to bacterial strains & $\mathbf{- 0 . 6 9}$ & $\mathbf{0 . 0 0 0 8 4}$ \\
Virulence versus R76 & $-\mathbf{0 . 6 8}$ & $\mathbf{0 . 0 0 0 9 1}$ \\
Virulence versus R47 & $\mathbf{- 0 . 6 2}$ & $\mathbf{0 . 0 0 3 2}$ \\
Virulence versus S19 & $\mathbf{- 0 . 5 5}$ & $\mathbf{0 . 0 1 2}$ \\
Aggressiveness versus R76 & -0.41 & 0.076 \\
Aggressiveness versus S19 & -0.36 & 0.12 \\
\hline Aggressiveness versus R47 & & \\
\hline
\end{tabular}

a Bold indicates significant correlations $(P<0.05)$. 
strains. Consequently, the different Pseudomonas strains may act through distinct modes of action. In a recent study focused on the isolate Rec01, we observed that different bacterial strains showed varying inhibition potential during different developmental stages of the pathogen (De Vrieze et al. 2018). Moreover, in the same study, we showed that the susceptibility of Rec01 to a single bacterial strain was different during in vitro and leaf disc experiments. Therefore, we selected six $P$. infestans strains varying in virulence and tested their susceptibility to the three Pseudomonas, R47, R76, and S19, in leaf disc assays (Fig. 6). We observed different susceptibility patterns. In addition, to Rec01, three other isolates ( $\mathrm{CH} 3, \mathrm{CH} 6 \mathrm{a}$, and $\mathrm{CH} 6 \mathrm{~b})$ were significantly inhibited by the three Pseudomonas strains. As mentioned for in vitro tests, three of these four isolates were fungicide-resistant, suggesting that biological control measures might offer a complementary spectrum of protection even when fungicide resistance has evolved in a population. The highly virulent $\mathrm{CH} 15$, which was only inhibited by R47 during in vitro experiments, showed the same susceptibility pattern during leaf disc experiments, whereas the moderately virulent $\mathrm{CH} 9$ was only inhibited by $\mathrm{S} 19$ in leaf discs, although it was more susceptible to R47 in vitro. This confirmed our earlier findings that sensitivity to biocontrol strains may strongly vary depending on the experimental conditions (in vitro versus leaf discs) (De Vrieze et al. 2018; Guyer et al. 2015). This also indicated the need for future experiments beyond the leaf disc infection assays performed in this study, which should be validated in further studies using wholeplant infection assays under controlled conditions and, ultimately, field experiments.

Altogether, our observations relative to the range of activity of potato-associated $P$ seudomonas strains against $P$. infestans showed broad-range inhibitory activity of selected Pseudomonas strains (such as R47), which extended over mating types, genotypes, virulence, aggressiveness, and fungicide resistance, and distinct responses of specific isolates to specific bacterial strains. Pseudomonas bacteria possess wide arsenals of antifungal compounds, antibiotics, toxins, and other secondary metabolites (Stringlis et al. 2018). For instance, Pseudomonas R47 is known to produce the inorganic volatile compound hydrogen cyanide $(\mathrm{HCN})$ and phenazines, both of which were shown to inhibit $P$. infestans in previous studies (Hunziker et al. 2015; Morrison et al. 2017). HCN is likely to be responsible for the complete absence of recovery of $P$. infestans isolates after exposure to R47 (Fig. 7). The two other strains tested do not emit $\mathrm{HCN}$, nor do they produce phenazines (De Vrieze et al. 2018). However, in previous studies, we have shown that the volatilomes of R76 and S19 harbor a complex set of volatile compounds with anti-Phytophthora activity (De Vrieze et al. 2015; Hunziker et al. 2015). Additionally, these strains might contain yetunknown nonvolatile anti-oomycete compounds. The observed inhibitory effects on $P$. infestans growth on exposure to the biocontrol strains might be caused by a single compound, but they are more likely to originate from a blend of molecules with different modes of action. Therefore, the use of bacteria offers significant advantages over synthetic molecules regarding resistance management because it is extremely unlikely that a $P$. infestans isolate would acquire resistance against all molecules responsible for the inhibition. Our attempt to determine whether $P$. infestans isolates exposed to the bacterial strains would partially lose their susceptibility to the biocontrol agents on repeated exposure revealed that the reverse was the case for all tested $P$. infestans isolates and bacterial strains (Fig. 7). This provides hope regarding the expected durability of such protective treatments, although further studies are needed to verify this hypothesis. In additional to the large and partially redundant set of antimicrobial compounds encoded in the genome of each of the selected Pseudomonas strains, combining strains with different modes of action might not only increase the reliability of protection on different cultivars, as shown previously (De Vrieze et al. 2018), but also extend the range of protective activity on genetically diverse pathogen strains, as suggested by the present study.

\section{ACKNOWLEDGMENTS}

The authors are grateful to Heinz Krebs, Eric Remolif, Suset Ulliel, and Eric Droz for technical help, to Brice Dupuis for access and management of facilities, and to Jean-Louis Rollot for providing in vitro plants. They also thank Tomke Musa for her assistance with establishing contact with the cantonal services that provided the $P$. infestans isolates.

\section{LITERATURE CITED}

Baker, F. B. 1974. Stability of two hierarchical grouping techniques case I: Sensitivity to data errors. J. Am. Stat. Assoc. 69:440-445.

Bengtsson, T., Weighill, D., Proux-Wéra, E., Levander, F., Resjö, S., Burra, D. D., et al. 2014. Proteomics and transcriptomics of the BABA-induced resistance response in potato using a novel functional annotation approach. BMC Genomics 15:315.

Brurberg, B. M., Elameen, A., Hong, V., Nærstad, R., Hermansen, A., Lehtinen, A., et al. 2011. Genetic analysis of Phytophthora infestans populations in the Nordic European countries reveals high genetic variability. Fungal Biol. 115:335-342.

Brylińska, M., Sobkowiak, S., Stefańczyk, E., and Śliwka, J. 2016. Potato cultivation system affects population structure of Phytophthora infestans. Fungal Ecol. 20:132-143.

Burra, D. D., Berkowitz, O., Hedley, P. E., Morris, J., Resjö, S., Levander, F., et al. 2014. Phosphite-induced changes of the transcriptome and secretome in Solanum tuberosum leading to resistance against Phytophthora infestans. BMC Plant Biol. 14:254.

Caulier, S., Gillis, A., Colau, G., Licciardi, F., Liépin, M., Desoignies, N., et al. 2018. Versatile antagonistic activities of soil-borne Bacillus spp. and Pseudomonas spp. against Phytophthora infestans and other potato pathogens. Front. Microbiol. 9:143.

Chmielarz, M., Sobkowiak, S., Debski, K., Cooke, D. E. L., Brurberg, M. B., and Śliwka, J. 2014. Diversity of Phytophthora infestans from Poland. Plant Pathol. 63:203-211.

Chowdappa, P., Nirmal Kumar, B. J., Madhura, S., Mohan Kumar, S. P., Myers, K. L., Fry, W. E., et al. 2015. Severe outbreaks of late blight on potato and tomato in South India caused by recent changes in the Phytophthora infestans population. Plant Pathol. 64:191-199.

Clinckemaillie, A., Decroës, A., van Aubel, G., Carrola dos Santos, S., Renard, M. E., Van Cutsem, P., et al. 2017. The novel elicitor COS-OGA enhances potato resistance to late blight. Plant Pathol. 66:818-825.

Cooke, D. E. L., Cano, L. M., Raffaele, S., Bain, R. A., Cooke, L. R., Etherington, G. J., et al. 2012. Genome analyses of an aggressive and invasive lineage of the Irish potato famine pathogen. PLOS 8:e1002940.

De Vrieze, M., Germanier, F., Vuille, N., and Weisskopf, L. 2018. Combining different potato-associated Pseudomonas strains for improved biocontrol of Phytophthora infestans. Front. Microbiol. 9:2573.

De Vrieze, M., Pandey, P., Bucheli, T. D., Varadarajan, A. R., Ahrens, C. H., Weisskopf, L., et al. 2015. Volatile organic compounds from native potatoassociated Pseudomonas as potential anti-oomycete agents. Front. Microbiol. 6:1-15.

Drenth, A., Tas, I. C. Q., and Govers, F. 1994. DNA fingerprinting uncovers a new sexually reproducing population of Phytophthora infestans in the Netherlands. Eur. J. Plant Pathol. 100:97-107.

Du, J., Verzaux, E., Chaparro-Garcia, A., Bijsterbosch, G., Keizer, L. C. P., Zhou, J., et al. 2015. Elicitin recognition confers enhanced resistance to Phytophthora infestans in potato. Nat. Plants 1:15034.

Floryszak-Wieczorek, J., Arasimowicz-Jelonek, M., and Abramowski, D. 2015. BABA-primed defense responses to Phytophthora infestans in the next vegetative progeny of potato. Front. Plant Sci. 6:1-9.

Forrer, H.-R., Vogelgsang, S., and Musa, T. 2017. Botanicals and phosphonate show potential to replace copper for control of potato late blight. J. Fungi (Basel) 3:65.

Fry, W. 2008. Phytophthora infestans: The plant (and R gene) destroyer. Mol. Plant Pathol. 9:385-402.

Fry, W. E., Myers, K., Roberts, P., McGrath, M. T., Everts, K., Secor, G. A., et al. 2013. The 2009 late blight pandemic in the Eastern United StatesCauses and results. Am. Phytopathol. Soc. 97:296-306.

Gallou, A., Lucero Mosquera, H. P., Cranenbrouck, S., Suárez, J. P., and Declerck, S. 2011. Mycorrhiza induced resistance in potato plantlets challenged by Phytophthora infestans. Physiol. Mol. Plant Pathol. 76: 20-26.

Gisi, U., Walder, F., Resheat-Eini, Z., Edel, D., and Sierotzki, H. 2011. Changes of genotype, sensitivity and aggressiveness in Phytophthora infestans isolates collected in European countries in 1997, 2006 and 2007. J. Phytopathol. 159:223-232.

Goodwin, S. B., Smart, C. D., Sandrock, R. W., Deahl, K. L., Punja, Z. K., and Fry, W. E. 1998. Genetic change within populations of Phytophthora 
infestans in the United States and Canada during 1994 to 1996: Role of migration and recombination. Phytopathology 88:939-949.

Guyer, A., De Vrieze, M., Bönisch, D., Gloor, R., Musa, T., Bodenhausen, N., et al. 2015. The anti-Phytophthora effect of selected potato-associated Pseudomonas strains: From the laboratory to the field. Front. Microbiol. 6: $1-13$.

Hadwiger, L. A., McDonel, H., and Glawe, D. 2015. Wild yeast strains as prospective candidates to induce resistance against potato late blight (Phytophthora infestans). Am. J. Potato Res. 92:379-386.

Haverkort, A. J., Struik, P. C., Visser, R. G. F., and Jacobsen, E. 2009. Applied biotechnology to combat late blight in potato caused by Phytophthora infestans. Potato Res. 52:249-264.

Hermansen, A., Hannukkala, A., Nærstad, R. H., and Brurberg, M. B. 2000. Variation in populations of Phytophthora infestans in Finland and Norway: Mating type, metalaxyl resistance and virulence phenotype. Plant Pathol. 49:11-22.

Horner, N. R., Grenville-Briggs, L. J., van West, P., West, P. V. A. N., and Avery, S. V. 2012. The oomycete Pythium oligandrum expresses putative effectors during mycoparasitism of Phytophthora infestans and is amenable to transformation. Fungal Biol. 116:24-41.

Hu, C.-H., Perez, F. G., Donahoo, R., McLeod, A., Myers, K., Ivors, K., et al. 2012. Recent genotypes of Phytophthora infestans in the Eastern United States reveal clonal populations and reappearance of mefenoxam sensitivity. Plant Dis. 96:1323-1330.

Hultberg, M., Bengtsson, T., and Liljeroth, E. 2010. Late blight on potato is suppressed by the biosurfactant-producing strain Pseudomonas koreensis 2.74 and its biosurfactant. BioControl 55:543-550.

Hunziker, L., Bönisch, D., Groenhagen, U., Bailly, A., Schulz, S., and Weisskopf, L. 2015. Pseudomonas strains naturally associated with potato plants produce volatiles with high potential for inhibition of Phytophthora infestans. Appl. Environ. Microbiol. 81:821-830.

Judelson, H. S., and Blanco, F. 2005. The spores of Phytophthora: Weapons of the plant destroyer. Nat. Rev. Microbiol. 3:47-58.

Kiiker, R., Hansen, M., Williams, I. H., Cooke, D. E. L., and Runno-Paurson, E. 2018. Outcome of sexual reproduction in the Phytophthora infestans population in Estonian potato fields. Eur. J. Plant Pathol. 152:395-407.

Li, Y., Van der Lee, T., Zhu, J. H., Jin, G. H., Lan, C. Z., Zhu, S. X., et al. 2013. Population structure of Phytophthora infestans in China-Geographic clusters and presence of the EU genotype Blue_13. Plant Pathol. 62:932-942.

Li, Y., van der Lee, T. A. J., Evenhuis, A., van den Bosch, G. B. M., van Bekkum, P. J., Förch, M. G., et al. 2012. Population dynamics of Phytophthora infestans in the Netherlands reveals expansion and spread of dominant clonal lineages and virulence in sexual offspring. Genes Genomes Genet. 2:1529-1540.

Liljeroth, E., Bengtsson, T., Wiik, L., and Andreasson, E. 2010. Induced resistance in potato to Phytophthora infestans-Effects of BABA in greenhouse and field tests with different potato varieties. Eur. J. Plant Pathol. 127:171-183.
McDonald, B. A., and Linde, C. 2002. Pathogen population genetics, evolutionary potential, and double resistance. Annu. Rev. Phytopathol. 40: 349-379.

Michalska, A. M., and Sobkowiak, S. 2016. Virulence and aggressiveness of Phytophthora infestans isolates collected in Poland from potato and tomato plants identified no strong specificity. Eur. J. Plant Pathol. 144: 325-336.

Montarry, J., Andrivon, D., Glais, I., Corbiere, R., Mialdea, G., and Delmotte, F. 2010. Microsatellite markers reveal two admixed genetic groups and an ongoing displacement within the French population of the invasive plant pathogen Phytophthora infestans. Mol. Ecol. 19:1965-1977.

Montes, M. S., Nielsen, B. J., Schmidt, S. G., Bødker, L., Kjøller, R., and Rosendahl, S. 2016. Population genetics of Phytophthora infestans in Denmark reveals dominantly clonal populations and specific alleles linked to metalaxyl-M resistance. Plant Pathol. 65:744-753.

Morrison, C. K., Arseneault, T., Novinscak, A., and Filion, M. 2017. Phenazine-1-carboxylic acid production by Pseudomonas fluorescens LBUM636 alters Phytophthora infestans' growth and late blight development. Phytopathology 107:273-279.

Musa-Steenblock, T., and Forrer, H.-R. 2005. Bio-PhytoPRE-a decision support system for late blight control in organic potato production in Switzerland. Pages 133-136 in: Beiträge zur 8. Wissenschaftstagung zum Ökologischen Landbau, Kassel.

Niks, R. E., Parlevliet, J. E., Lindhout, P., and Bai, Y. 2019. Breeding Crops with Resistance to Diseases and Pests. Wageningen Academic Publishers, Wageningen, The Netherlands.

Samen, F. M. A., Secor, G. A., and Gudmestad, N. C. 2003. Variability in virulence among asexual progenies of Phytophthora infestans. Phytopathology 93:293-304.

Si-Ammour, A., Mauch-Mani, B., and Mauch, F. 2003. Quantification of induced resistance against Phytophthora species expressing GFP as a vital marker: $\beta$-aminobutyric acid but not BTH protects potato and Arabidopsis from infection. Mol. Plant Pathol. 4:237-248.

Sjöholm, L., Andersson, B., Högberg, N., Widmark, A. K., and Yuen, J. 2013. Genotypic diversity and migration patterns of Phytophthora infestans in the Nordic countries. Fungal Biol. 117:722-730.

Stringlis, I. A., Zhang, H., Pieterse, C. M. J., Bolton, M. D., and de Jonge, R. 2018. Microbial small molecules-weapons of plant subversion. Nat. Prod. Rep. 35:410-433.

Widmark, A. K., Andersson, B., Cassel-Lundhagen, A., Sandström, M., and Yuen, J. E. 2007. Phytophthora infestans in a single field in southwest Sweden early in spring: Symptoms, spatial distribution and genotypic variation. Plant Pathol. 56:573-579.

Yao, Y., Li, Y., Chen, Z., Zheng, B., Zhang, L., Niu, B., et al. 2016. Biological control of potato late blight using isolates of Trichoderma. Am. J. Potato Res. 93:33-42.

Yuen, J. E., and Andersson, B. 2013. What is the evidence for sexual reproduction of Phytophthora infestans in Europe? Plant Pathol. 62:485-491. 